\title{
Inhibition of Neuroblastoma Cell Growth by Difluoromethylornithine (DFMO) and Bortezomib through Suppression of LIN28 and MYCN
}

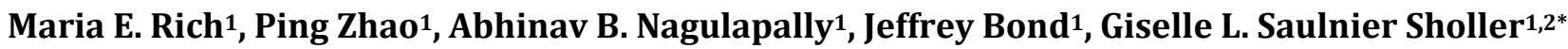 \\ ${ }^{1}$ Pediatric Oncology Research Program, Helen DeVos Children's Hospital, Grand Rapids, MI, USA \\ ${ }^{2}$ College of Human Medicine, Michigan State University, Grand Rapids, MI, USA \\ Email: *giselle.saulniersholler@helendevoschildrens.org
}

How to cite this paper: Rich, M.E., Zhao, P., Nagulapally, A.B., Bond, J. and Sholler, G.L.S. (2017) Inhibition of Neuroblastoma Cell Growth by Difluoromethylornithine (DFMO) and Bortezomib through Suppression of LIN28 and MYCN. Journal of Cancer Therapy, 8, 561-578.

https://doi.org/10.4236/jct.2017.86048

Received: May 4, 2017

Accepted: June 18, 2017

Published: June 21, 2017

Copyright $\odot 2017$ by authors and Scientific Research Publishing Inc. This work is licensed under the Creative Commons Attribution International License (CC BY 4.0).

http://creativecommons.org/licenses/by/4.0/

(c) $\underset{\mathrm{EY}}{(i)}$ Open Access

\begin{abstract}
Neuroblastoma (NB) is the most common childhood cancer arising from the nervous system. Many high-risk neuroblastoma (HRNB) patients develop relapse after initial response to induction treatment and overall long term survival remains poor (less than 60\%), emphasizing the need for new therapeutic approaches and more effective treatments. Combination therapies present a favorable approach to improve efficacy, decrease toxicity, and reduce development of drug resistance. Difluoromethylornithine (DFMO) has shown promise in recent clinical trials as a therapeutic agent in treating HRNB. Proteasomes are known to play an important role in tumor cell growth. Bortezomib was the first proteasome inhibitor shown to have anticancer activity clinically. In this study we explore the mechanistic and therapeutic effects of the novel drug combination of DFMO and bortezomib in NB. Cell proliferation studies demonstrated synergistic inhibition of NB cell growth. Bortezomib induced cleaved caspase-3 apoptotic pathway whereas DFMO induced a cytostatic effect on NB cells. Western blot analyses demonstrated down regulation of MYCN, LIN28 and NF-kB in response to DFMO and bortezomib, pathways that are important in cancer stem cells. A decrease in ATP-per-cell when treated with combination therapy suggests inhibition of glycolytic metabolism in NB cells. DFMO as a single agent or in combination with bortezomib significantly reduced tumor growth in xenograft mice. Given the lack of effective treatments, DFMO coupled with bortezomib offers a potential new therapeutic treatment for children with NB.
\end{abstract}

\section{Keywords}

Neuroblastoma, DFMO, Bortezomib, LIN28B, Glycolytic Metabolism 


\section{Introduction}

The most common extracranial solid pediatric tumor, neuroblastoma (NB), is a heterogeneous malignancy that develops throughout the sympathetic nervous system from neural crest stem cells, often in the adrenal glands [1]. Characteristically, NB is responsible for $8 \%-10 \%$ of all cancer in children and $15 \%$ of pediatric cancer deaths, occurring most commonly in children between 0 and 4 years old [2]. More than 600 new cases of NB are diagnosed in children in the United States per year, of which, approximately $70 \%$ have metastatic disease [3]. Due to a high rate of tumor relapse, less than $60 \%$ of patients with high-risk disease reach long-term survival [4] [5].

High incidence of metastatic disease and relapse in high-risk NB is hypothesized to be due to the presence of cancer stem cells (CSCs) that have capacity to self-renew and initiate new tumor formation [6] [7] [8]. The existence of CSCs has been widely identified and described in leukemia and several solid tumors including breast, brain, pancreatic, liver, skin, and colon [9] [10] [11]. In regards to NB, researchers have isolated CSCs from NB tumors [12], providing further support for new therapeutic targets of CSCs in NB in order to improve prognosis and reduce the rate of tumor relapse. New studies have shown that LIN28 has profound effects on normal and malignant stem cells through the posttranscriptional downregulation of the microRNA Let-7 via a double negative feedback loop [13] [14]. LIN28 protein promotes stem cell self-renewal and is highly expressed during embryogenesis, while expression of the protein gradually diminishes and disappears by adulthood [15]. High levels of LIN28 were found in a sub-population of cells with CSC properties in many cancer types [16]. The role of LIN28 in stemness of CSC is further supported by the findings that forced expression of LIN28 promotes the expression of CSC markers as well as the selfrenewal capability of CSCs, while knock-down has the opposite effect [17] [18]. Enhanced expression of LIN28 was also shown to induce resistance to chemotherapy-induced apoptosis [19] [20]. Neural crest stem cells, the cells in which NB originally develops, express high levels of LIN28B during embryonic development [1]. LIN28 overexpression in neural crest cells leads to NB formation in mice [21]. Overexpression of LIN28 and its homolog LIN28B are common in NB and correlate with poor outcomes [14] [21]. The LIN28/Let-7 axis further regulates glycolytic metabolism through the regulation of the NF-kB inflammatory loop. NF-kB inflammatory loop interacts with LIN28 protein via a positive feedback loop, where overexpression of NF-kB factors p50 and p65 increase LIN28 protein. Due to the important role of the LIN28/Let-7 axis in glycolytic metabolism as well as the importance of glycolytic metabolic activity for the assembly of ATP in CSCs, manipulating the LIN28 and Let-7 pathway in cancer cells may provide novel therapeutic opportunities in cancer.

Polyamines, aliphatic cations that control DNA-protein and protein-protein interactions, have been found to play an important role upstream of the LIN28/Let-7 pathway [22]. Polyamine biosynthesis is directly regulated by orni- 
thine decarboxylase (ODC): a rate-limiting enzyme overexpressed in several NB patients and associated with poor prognosis [23]. The drug DFMO is a known inhibitor of ODC. Furthermore, three different NB patients enrolled in a DFMO clinical trial had reduced tumor metabolic activity as measured by Positron Emission Tomography (PET) scans after starting DFMO treatment with prolonged stabilization of disease [24]. Recent preclinical studies have shown that DFMO treatment reduced polyamine levels, reversed the LIN28/Let-7 axis, reduced glycolytic metabolism both in vitro and in vivo, and suggested that DFMO may be targeting CSCs in NB [22] [25]. Used in combination with other agents that also target CSC pathways, DFMO could offer a novel chemotherapeutic approach to increase long-term survival for patients with $\mathrm{NB}$, as well as several other cancers associated with overexpression of LIN28.

Bortezomib (PS-341, Velcade) is a potent and selective proteasome inhibitor, shown to sensitize human colorectal cancer cell lines to camptothecin analogues [26]. This drug is approved by the US FDA for treatment of multiple myeloma and relapsed/refractory multiple myeloma [27]. Proteosome activity is associated with the activation of NF-kB signaling pathway due to the degradation of IkB protein by proteasomes [28]. Since increased LIN28 expression correlated with increased NF-kB transcription factor [29], bortezomib may further inhibit LIN28 mediated pathways in NB including glycolytic metabolic activity. Several studies have identified cell death with bortezomib in NB [30] [31] [32]. In order to overcome drug resistance in several tumors, numerous studies have evaluated the antitumor effects of bortezomib in combination with other therapeutic drugs [33].

The present study aimed to investigate both the therapeutic impact and mechanism of DFMO and bortezomib drug combination on NB cells. We hypothesized that the combination treatment would synergistically inhibit cellular proliferation, impact protein expression in the LIN28/Let-7 pathway, reduce glycolytic metabolic activity in NB cancer cells, and reduce tumor growth in xenograft mice. The proposed DFMO and bortezomib target pathways are summarized in Figure 1. Results of this study revealed that synergistic effect of DFMO and bortezomib was observed in cells overexpressing LIN28 and MYCN but not in cells with low LIN28 expression. These findings suggest that combined drug therapy of DFMO and bortezomib may be beneficial to HRNB patients with MYCN amplification and with high LIN28 expression.

\section{Materials and Methods}

\subsection{Compounds and Reagents}

The ODC inhibitor Difluoromethylornithine or DFMO (kindly provided by Dr. Patrick Woster, Medical University of South Carolina) was dissolved at $1 \mathrm{M}$ in $\mathrm{H}_{2} \mathrm{O}$. Proteosome inhibitor Bortezomib (purchased from LC Laboratory, Woburn, MA) was dissolved at $10 \mathrm{mM}$ in dimethyl sulfoxide (DMSO). Both drug solutions were stored in small aliquots at $-20^{\circ} \mathrm{C}$ and diluted with culture media within two hours of introducing drugs to neuroblastoma cell lines in vitro. 


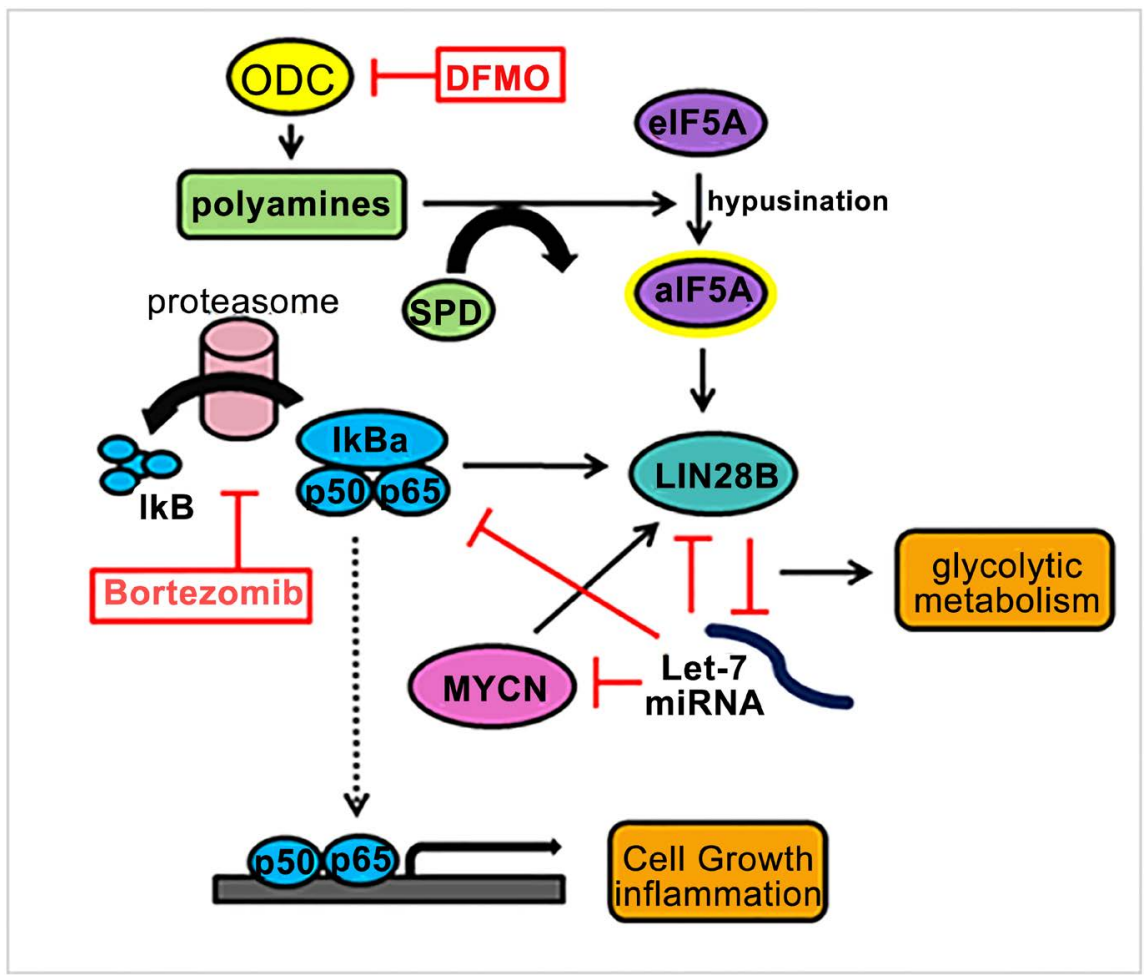

Figure 1. Proposed pathway of DFMO and Bortezomib action on LIN28/Let-7 axis, NF-kB, and glycolytic metabolism in NB. DFMO irreversibly inhibits ODC, leading to reduced hypusination of eIF5A and downregulation of LIN28 and MYCN. While bortezomib inhibits proteasomal-mediated degradation of $\mathrm{IkB}$, thereby preventing NF-kB activation. This inhibits NF-kB mediated LIN28 transcription and its effect on tumor growth.

\subsection{Cell Lines and Culture}

Single and combination drug tests were conducted on two human NB cell lines: BE(2)-C (ATCC, Manassas, VA) and SMS-KCNR (graciously donated by Dr. John Maris in 2004, The Children's Hospital of Philadelphia, PA). Both cell lines tested were MYCN amplified. Cell lines were certified by Cell-Check analysis (IDEXX BioResearch, Columbia, MO). Cells were cultured in RPMI-1640 with $10 \%$ ( $\mathrm{vol} / \mathrm{vol}$ ) certified fetal bovine serum (FBS), $100 \mathrm{U} / \mathrm{mL}$ penicillin, and 100 $\mathrm{mg} / \mathrm{mL}$ streptomycin. Incubation was at $37^{\circ} \mathrm{C}$ with $5 \% \mathrm{CO}_{2}$. All cell culture reagents were purchased from Life Technologies (Grand Island, NY).

Cells were grown in 6-well or 96-well plates. For all experiments using 96-well plates with $72 \mathrm{hr}$ time points, $\mathrm{BE}(2)-\mathrm{C}$ cells were plated at 2500 cells/well and SMS-KCNR cells were plated at 4500 cells/well. For $48 \mathrm{hr}$ time points with 96-well plates, $\mathrm{BE}(2)-\mathrm{C}$ cells were plated at 3000 cells/well and SMS-KCNR cells were plated at 5000 cells/well. In 6-well plates, BE(2)-C cells were plated at 100,000 cells/well. All plated cells were allowed to adhere overnight and grown to $60 \%-70 \%$ confluence within the well prior to drug treatment.

\subsection{Cell Viability}

Calcein AM fluorescent assay (Life Technologies, Grand Island, NY) was used to 
determine cell viability in 96-well plates. Cells were treated with increasing concentrations of DFMO $(0.15-40 \mathrm{mM})$ or bortezomib $(0.31-40 \mathrm{nM})$ in RPMI1640 with $10 \%$ FBS for 72 hrs. After $48 \mathrm{hrs,} \mathrm{drug} \mathrm{solutions} \mathrm{were} \mathrm{refreshed.} \mathrm{Once}$ cells underwent incubation with drug for $72 \mathrm{hr}$, the medium was aspirated and replaced with phenol-red free RPMI medium containing $2 \mu \mathrm{g} / \mathrm{mL}$ Calcein AM. After 30 minutes incubation at $37^{\circ} \mathrm{C}$, fluorescence was measured at $480 \mathrm{ex} / 520 \mathrm{em}$ with a BioTek plate reader (BioTek Instruments Inc., Winooski, VT).

\subsection{Ray Design Analysis}

Calcein AM fluorescent assay (Life Technologies) was additionally employed for ray design cell viability analyses with DFMO in combination with bortezomib. $\mathrm{BE}(2)-\mathrm{C}$ and SMS-KCNR cells were plated in a 96-well plates. Drug treatment concentrations were determined for 6 rays of 9 dilutions. After 48 hr, drug combinations were refreshed in each well. At $72 \mathrm{hr}$ post-initial addition of drug, the Calcein AM assay was performed as previously described. Isobolograms of drug effects (cell proliferation) were plotted with concentrations of DFMO and bortozomib on $\mathrm{x}$-axis and $\mathrm{y}$-axis, respectively. The points represented each Ray. Lower cell proliferation indicates higher synergistic effect of the drug combination. Points below the line of additivity (red line) are considered synergistic (when points are well below the line) or additive effect (when the points are close to the line).

\subsection{Cell Lysis and Protein Assay}

$\mathrm{BE}(2)-\mathrm{C}$ cells in 6-well plates were treated with $2.5 \mathrm{mM}$ DFMO, $5 \mathrm{nM}$ bortezomib, or combination of both $2.5 \mathrm{mM}$ DFMO coupled with $5 \mathrm{nM}$ bortezomib. SMS-KCNR cells in 6-well plates were treated with $2.5 \mathrm{mM}$ DFMO, $1 \mathrm{nM}$ bortezomib, or combination of both $2.5 \mathrm{mM}$ DFMO coupled with $1 \mathrm{nM}$ bortezomib. Drug solutions were prepared in RPMI-1640 with 10\% FBS. Drug supplemented medium was refreshed after $48 \mathrm{hrs}$ for $72 \mathrm{hr}$ time points. DMSO was used as vehicle control. Cells were lysed with RIPA lysis buffer (Cell Signaling, Danvers, MA), supplemented with a complete protease inhibitor (Roche, Madison, WI), and cell lysates were collected after $48 \mathrm{hr}$ and $72 \mathrm{hr}$ of drug treatment. Cell lysates were collected and frozen at $-80^{\circ} \mathrm{C}$ for a minimum of $24 \mathrm{hr}$ to ensure complete cell lysis. Samples were thawed and centrifuged at 13,500 rpm for $15 \mathrm{mi}-$ nutes and supernatant was collected into new eppendorf tubes. Total protein concentrations present within cell lysates were determined by Bradford protein assay (Bio-Rad, Hercules, CA).

\subsection{Western Blot Analysis}

Samples were diluted in RIPA lysis buffer to yield equal protein concentrations within each sample. Fifty micrograms of total protein for BE(2)-C cells and SMS-KCNR was loaded per lane. Gels were semi-dry transferred to nitrocellulose membranes using the Turbo Transfer system with Turbo Transfer buffer (Bio-Rad). Primary antibodies used were: rabbit polyclonal LIN28B, rabbit po- 
lyclonal MYCN, rabbit polyclonal NF-kB, rabbit polyclonal Cleaved Caspase-3 and Caspase-3 (Cell Signaling), and goat polyclonal $\beta$-actin (Santa Cruz Biotechnology). Goat anti-rabbit and Donkey anti-goat HRP-IgG secondary antibodies were used (Santa Cruz Biotechnology). Protein bands were detected with western ECL substrate (Bio-Rad) by chemiluminescence on ChemiDoc ${ }^{\mathrm{TM}}$ MP System (Bio-Rad). Optic density of each band compared to the normalized actin bands was determined using Image Lab Software (Bio-Rad). A fold-change of $\geq 2$ was used as a statistical parameter for this.

\subsection{ATP per Cell Assay}

The Cell Titer GLO luminescent assay (Promega, Madison, WI), which measures total ATP levels, was combined with the CyQuant fluorescent DNA assay (Invitrogen, Grand Island, NY), an indicator of total cellular DNA present, to measure ATP level per cell. BE(2)-C and SMS-KCNR cells were plated in 96-well black-walled plates. Cells were treated for $48 \mathrm{hrs}$ with DFMO $(5 \mathrm{mM})$ coupled with bortezomib ( $5 \mathrm{nM}$ and $4 \mathrm{nM}$ for BE(2)-C and SMS-KCNR cells, respectively) in RPMI-1640 with 10\% FBS. 1\% PBS in RPMI-1640 was used as control. After $48 \mathrm{hrs}$, medium was aspirated and replaced with Cell Titer GLO reagent (lysis buffer mixed with Cell Titer GLO substrate, diluted with PBS 1:1) supplemented with CyQuant stock solution ( $50 \mu \mathrm{L}$ dye per $10 \mathrm{~mL}$ Cell Titer GLO reagent). Plates were rocked on an orbital shaker for 3 minutes at $20^{\circ} \mathrm{C}$ to induce cell lysis, and then were incubated an additional 10 minutes at $20^{\circ} \mathrm{C}$ to allow luminescent signal stabilization. Luminescence and fluorescence data were recorded using a Wallac plate reader and Envision software (GMI Inc., Ramsey, MN). Cell Titer GLO data were divided by CyQuant data and normalized to vehicle wells in order to analyze data.

\subsection{In Vivo Studies}

In vivo drug studies were conducted with six-week-old female nude mice (nu/ nu) (Charles River Laboratories, Portage, MI). Mice were housed in pathogenfree conditions and cared for in accordance with the Institutional Animal Care and Use Committee (IACUC) standards. All mice received $2 \times 10^{6}$ SMS- KCNR cells suspended in $100 \mu \mathrm{L}$ of Matrigel (BD Biosciences, San Jose, CA) via subcutaneous injection into their right flank. Mice were then separated into four experimental treatment groups $(n=9)$ when their tumors reached between 100 and $200 \mathrm{~mm}^{3}$ : vehicle control, DFMO-treated, bortezomib-treated, and combination-treated. At time of grouping, each experimental group had the same average tumor volume. Vehicle control mice received $10 \mu \mathrm{L}$ PBS via intraperitoneal injection (IP) twice per week. 2\% DFMO was administered in drinking water (4 g DFMO into $200 \mathrm{~mL} \mathrm{H}_{2} \mathrm{O}$ ) for DFMO-treated and combination-treated mice. Bortezomib was injected $0.5 \mathrm{mg} / \mathrm{kg}$ IP injection twice weekly for bortezomibtreated and combination-treated mice. Drinking water was changed twice weekly. Caliper tumor measurements were completed twice weekly at time of drug treatment. Once tumors reached $2.0 \mathrm{~cm}^{3}$, tumor measurements were recorded 
daily. Tumor volume was determined by the equation length $\mathrm{x}$ width $\mathrm{x}$ depth $\mathrm{x}$ 0.52 . Throughout the study, each individual mouse was weighed to confirm that the mice maintained a stable and healthy weight at approximately $20 \mathrm{~g}( \pm 15 \%)$.

\subsection{Statistical Analysis}

Cell viability experiments were replicated $(\mathrm{n}=2)$ for statistical significance. Dose-response curves are not described well by logistic models so $\mathrm{IC}_{50}$ values were estimated by monotone regression using the isoreg procedure of the $R[R$ Core Team (2016). R: A language and environment for statistical computing. R Foundation for Statistical Computing, Vienna, Austria. URL

https://www.R-project.org/] ATP-per-cell analysis data was analyzed for normality via the Shapiro-Wilks Test, log-transformed, and then analyzed using a two-way analysis of variance (ANOVA). In vivo data was analyzed by two way anova to calculate significance among groups using $\mathrm{R}$ software.

\section{Results}

\subsection{DFMO and Bortezomib Inhibit NB Cell Viability}

The effect of DFMO or bortezomib on NB cell viability as independent therapeutic treatments was determined and quantified in two NB cell lines, $\mathrm{BE}(2)-\mathrm{C}$ and SMS-KCNR NB cells, using the Calcein AM fluorescent assay. Both drugs reduced cell proportions (\% of viable cells relative to control) (Figure 2(A) Figure 2(B)). Both cell lines exhibited DFMO dose-response curves was estimated using monotone regression. The BE(2)-C and SMS-KCNR cell lines exhibited comparable sensitivity to DFMO based on IC50 values of $29 \mathrm{mM}$ and $28 \mathrm{mM}$, respectively (Figure $2(\mathrm{~A})$ ). There was a reduction in the cell viability at the lowest DFMO concentrations tested $[\sim 30 \%$ for $\mathrm{BE}(2)-\mathrm{C}$ and $\sim 10 \%$ for SMS$\mathrm{KCNR}$, showing regions of moderate and then steep slope in the dose-response curve. The changes in slope reflect impacts of DFMO on both cell division and cell death; the observed behavior is suggestive of cytostatic activity at low doses and cytotoxic activity at higher doses.

Bortezomib was cytotoxic to both experimental NB cell lines at a lower concentration of drug than that required for cytotoxic response with DFMO. Cell viability analysis indicated an $\mathrm{IC}_{50}$ value of $7.5 \mathrm{nM}$ bortezomib for $\mathrm{BE}(2)-\mathrm{C}$ cells and $3.1 \mathrm{nM}$ bortezomib for SMS-KCNR cells, indicative of sensitivity to bortezomib in both BE(2)-C and SMS-KCNR NB cell line (Figure 2(A) Figure 2 (B)). These results are consistent with previously published IC50 values for additional NB cell lines [32] [34] [35].

\subsection{DFMO in Combination with Bortezomib Inhibits NB Cell Viability in a Synergistic/Additive Manner}

Calcein AM fluorescent assays were performed to analyze the effect of DFMO coupled with bortezomib on BE(2)-C and SMS-KCNR cell proliferation. Cell lines were treated with DFMO in combination with bortezomib at varying concentrations of each drug (0.095 - $190 \mathrm{mM}$ DFMO; 0.055 - $55 \mathrm{nM}$ bortezomib) in 
A

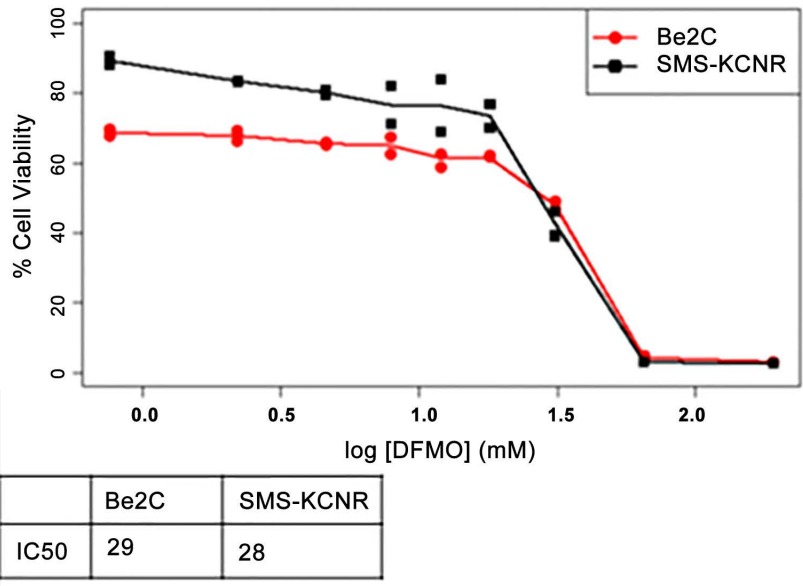

B

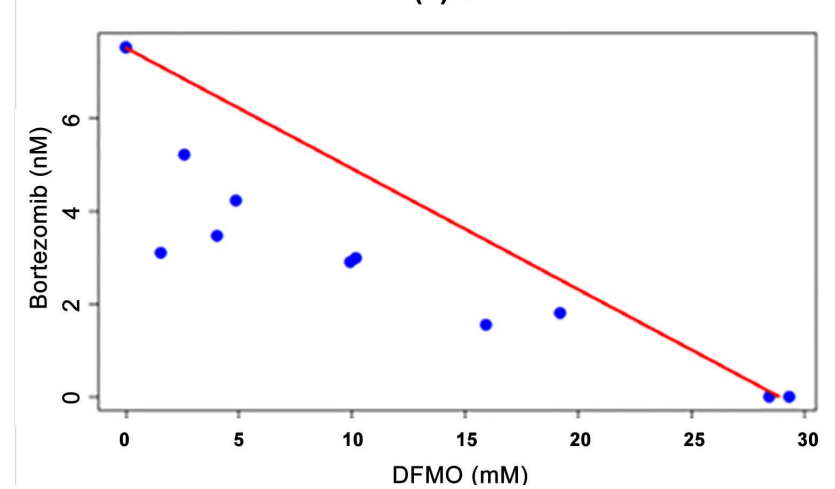

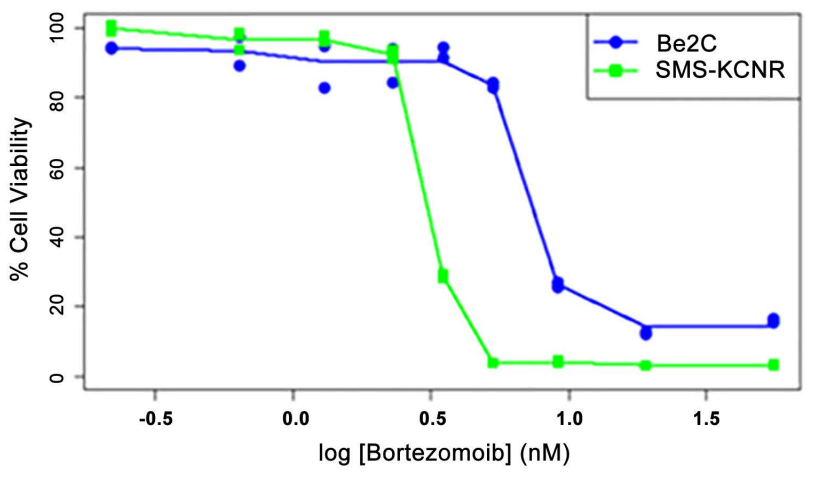

\begin{tabular}{|l|l|l|}
\hline & Be2C & SMS-KCNR \\
\hline IC50 & 7.5 & 3.1 \\
\hline
\end{tabular}

SMS-KCNR 72h

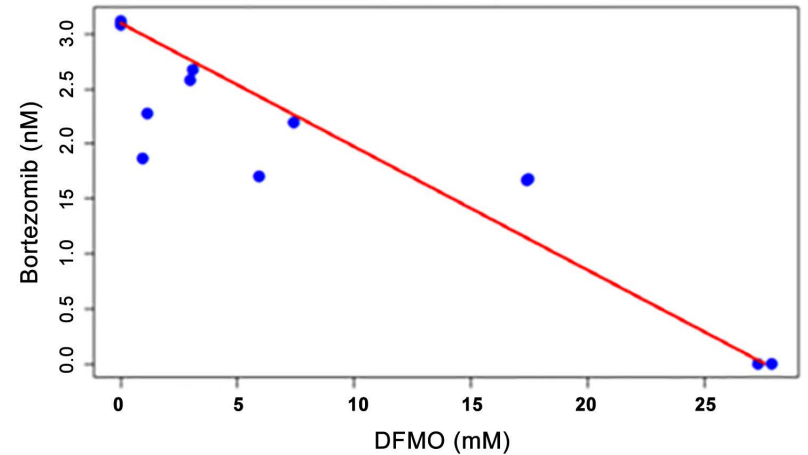

Figure 2. DFMO and Bortezomib inhibit NB cell proliferation. (A) IC50 values of DFMO and bortezomib in BE(2)-C and SMS-KCNR cells were calculated $72 \mathrm{hr}$ post-introduction of drug treatment using Calcein AM fluorescent assays. Treatments of DFMO (ranging from 0.095 - $190 \mathrm{mM}$ ) or bortezomib (ranging from 0.055 - $55 \mathrm{nM}$ ) were refreshed after 48 hr. (B) Six Rays were performed for each cell line and isobolograms of drug effects were plotted. Each point represents a ray. For Be(2)-C cells, points are well below the line of additivity suggesting a synergistic effect whereas points are closer to the line for SMS-KCNR cells suggesting an additive effect.

six dilution series (rays) at constant drug concentration ratio. Pairs of drug concentrations associated with 50\% proportion (points in (Figure 2(B)) fall almost exclusively below the line of additivity (the null hypothesis of Lowe additivity), a result that was pronounced for $\mathrm{BE}(2)-\mathrm{C}$ cells. This provides evidence for synergism based on comparison with Loewe additivity.

\subsection{Effect of DFMO and Bortezomib on the Expression of LIN28B, MYCN and NF-kB Proteins in NB Cells}

BE(2)-C and SMS-KCNR cells were treated with DFMO (2.5 mM) or bortezomib ( $5 \mathrm{nM}, \mathrm{BE}(2)-\mathrm{C}$ or $2 \mathrm{nM}$, SMS-KCNR) or a combination of both for $48 \mathrm{hr}$ or $72 \mathrm{hr}$. Expression of LIN28B, MYCN and NF-kB were examined by Western Blot analyses and quantification was performed as described in material and methods. In BE(2)-C cells, expression of LIN28B, MYCN and NF-kB were inhibited by treatment with DFMO alone or bortezomib alone, which was further 
inhibited by combination treatment at both time points (Figure 3(A)). Treatment of SMS-KCNR cells shows a similar but less pronounced pattern to $\mathrm{BE}(2)-\mathrm{C}$.

\subsection{Effect of DFMO and Bortezomib on the Apoptosis Marker Cleaved Caspase- 3 in NB Cells}

To examine whether DFMO or bortezomib induced apoptotic pathways in NB cells, BE(2)-C and SMS-KCNR cells were treated as above and expression of cleaved caspase- 3 and total caspase- 3 were examined by western blot analyses. For $\mathrm{BE}(2)-\mathrm{C}$ cells, there was an increase in cleaved caspase-3 expression in bortezomib and combination treated groups but not in the DFMO treated group at

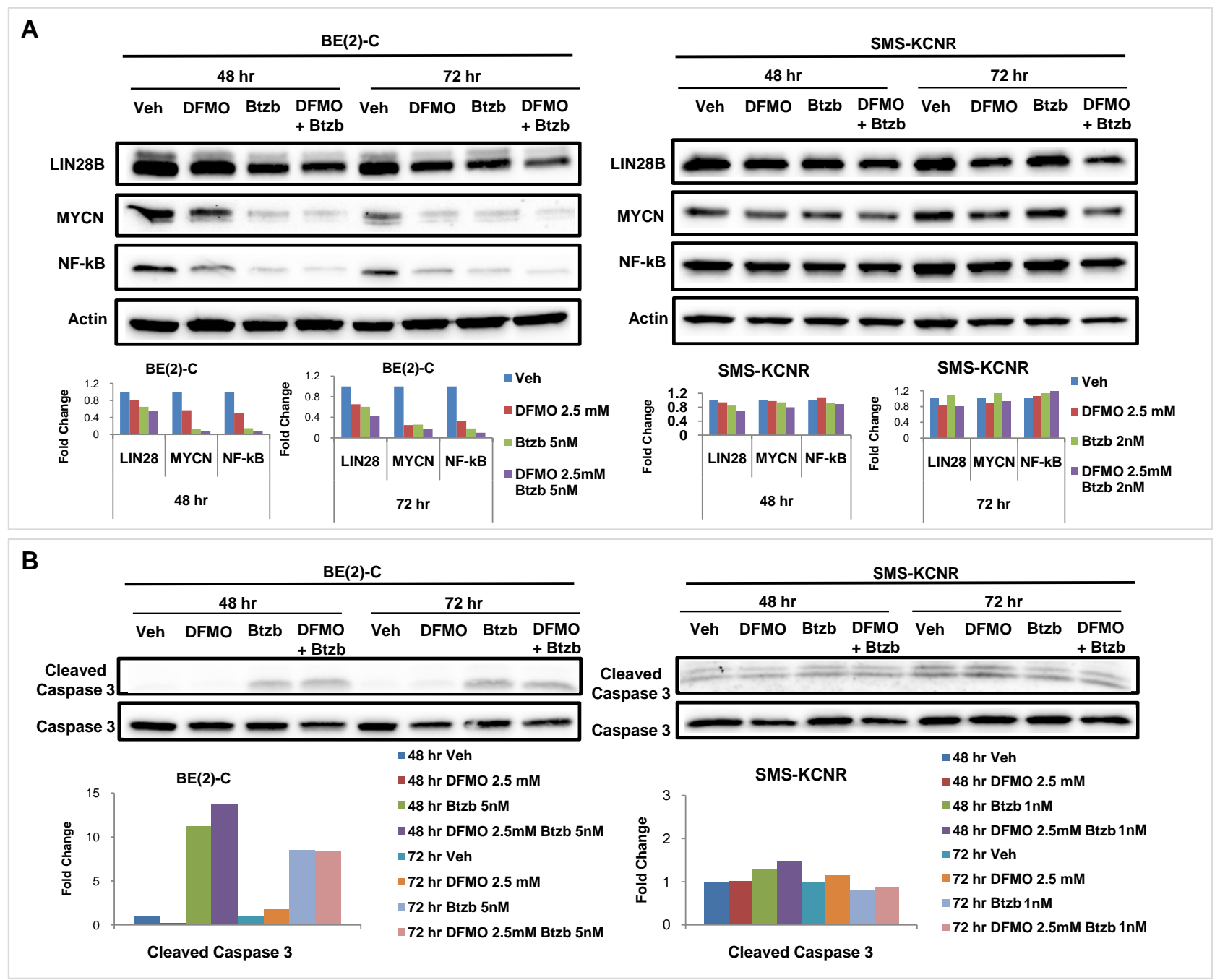

Figure 3. Combination treatment of DFMO and bortezomib inhibits LIN28 pathway. (A) BE(2)-C and SMS-KCNR cells were treated with D FMO (2.5 mM), bortezomib (5 nM for BE(2)-C, and $2 \mathrm{nM}$ for SMS-KCNR cells), or a combination of both drugs for $48 \mathrm{hr}$ and $72 \mathrm{hr}$. The expression of LIN28, MYCN, and NF-kB were analyzed by Western blot. Actin was used as loading control. (B) Western blot analysis was performed to examine cleaved caspase-3 and total caspase-3 in BE(2)-C and SMS-KCNR cells treated DFMO (2.5 mM), bortezomib ( $5 \mathrm{nM}$ for BE(2)-C, and $1 \mathrm{nM}$ for SMS-KCNR cells), or a combination of both drugs for $48 \mathrm{hr}$ and $72 \mathrm{hr}$. Relative intensities of the bands were normalized to vehicle controls. Western blots were repeated at least three times. 
both $48 \mathrm{hr}$ and $72 \mathrm{hr}$ (Figure 3(B)). Expression of total caspase-3 remains unchanged. There was minimal change in cleaved caspase- 3 or total caspase- 3 protein levels in SMS-KCNR cells with a slight increase in the treatment groups as compared to vehicle at 48 hours (Figure 3(B)).

\subsection{DFMO and Bortezomib Inhibit Glycolytic Metabolism in NB Cells}

In order to quantify the combination effect of DFMO and bortezomib on glycolytic metabolic activity in NB cell lines, ATP levels in treated-NB cells were measured by Cell Titer GLO luminescent assay coupled with CyQuant fluorescent DNA assays, which measure total DNA. Combination of these results measures ATP/Cell. BE(2)-C and SMS-KCNR cells were treated with DFMO (5 $\mathrm{mM}$ ) and bortezomib (5 $\mathrm{nM}$ or $4 \mathrm{nM}$ respectively) for 48 hours and ATP-percell analyses were performed $(n=3)$. Both NB cell lines exhibited significant decreased in ATP-per-cell activity with combination treatment as compared to DFMO or bortezomib as single agents, $P<0.001$ in all groups (Figure 4).

\subsection{DFMO and Bortezomib Exhibit Antitumor Activity in Tumor-Bearing Mice}

SMS-KCNR cells were injected subcutaneously in nude mice as described in material and methods. When tumors were palpable at 7 - 10 days, mice were

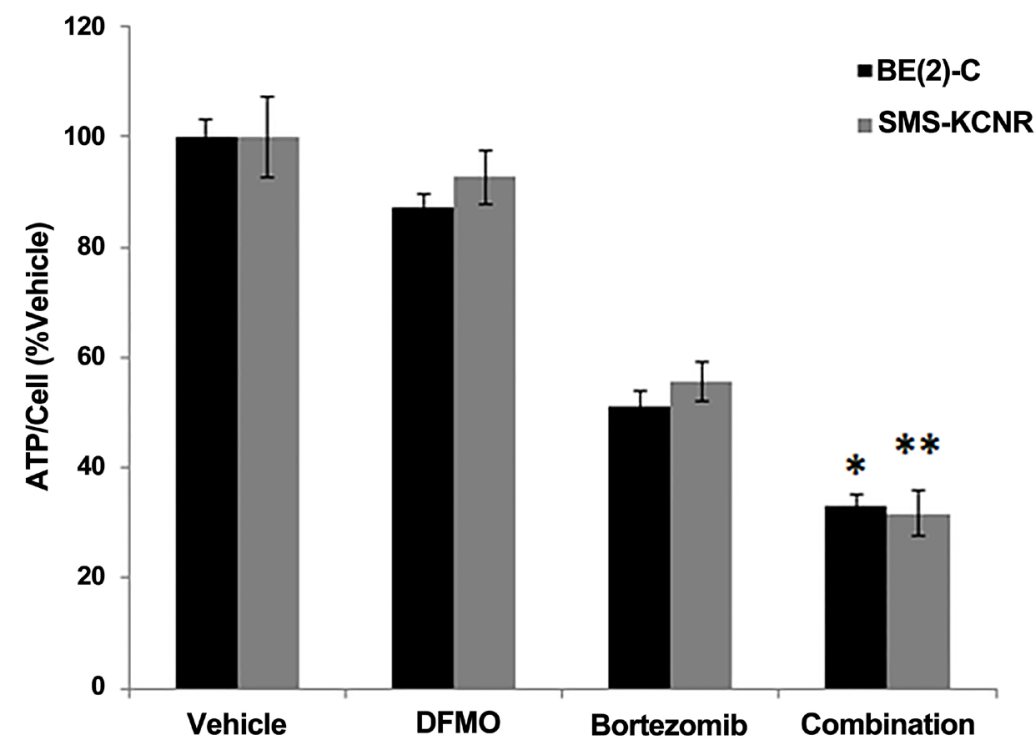

Figure 4. Combination treatment of DFMO and Bortezomib reduced cellular glycolytic metabolic activity in NB cell lines. $\mathrm{BE}(2)-\mathrm{C}$ and SMS-KCNR NB cells were treated with DFMO (2.5 mM), bortezomib (5 $\mathrm{nM}$ for BE(2)-C, and $4 \mathrm{nM}$ for SMS-KCNR cells), or a combination of both drugs for $48 \mathrm{hr}$. ATP present were measured by Cell Titer GLO luminescent assay. All data are presented as percent of vehicle control. ${ }^{*} \mathrm{p}=5.79561 \mathrm{E}-12$ and 2.31565E-06 in combination treatment compared to DFMO or bortezomib single agent therapies respectively in $\mathrm{BE}(2)-\mathrm{C}$ cells; ${ }^{* *} \mathrm{p}=2.854 \mathrm{E}-08$ and $6.91171 \mathrm{E}-06$ in combination treatment compared to DFMO or bortezomib single agent therapies respectively in SMS-KCNR cells. 
treated with either vehicle (10 $\mu \mathrm{L}$ PBS, IP, twice per week), DFMO (2\% in drinking water), bortezomib $(0.5 \mathrm{mg} / \mathrm{kg}$, IP, twice weekly), or combination of DFMO and bortezomib (9 mice per group). We found that DFMO as a single agent therapy or in combination with bortezomib can notably decrease tumor volume compared to vehicle control (Figure 5(A)). Bortezomib, as single agent, had no significant effect on tumor growth as compared to vehicle (Figure 5(A)). These results were further confirmed by growth curve analysis which revealed that DFMO alone or in combination with bortezomib significantly suppressed tumor growth $(p<0.05)$ on day 22 , but not by bortezomib as single agent (Figure $5(B)$ ). Mice treated with combination of DFMO and bortezomib had significantly higher time-to-threshold tumor volume of $2500 \mathrm{~mm}^{3}$ as compared to vehicle treated group with a $\mathrm{p}$ value of 0.01 (Figure 5(B)).

\section{Discussion}

Combination drug therapies offered several advantages such as better efficacy, decreased toxicity, and reduced development of drug resistance. These potential benefits result in an increased interest in combination therapies for the treatment of high risk tumors including neuroblastoma. For the first time, this study investigates the combined mechanistic and therapeutic effects of DFMO and bortezomib drug combination on NB cell lines, BE(2)-C and SMS-KCNR. Our results demonstrated that both drugs as single agents inhibited NB cell growth. Combination of DFMO and bortezomib produced a synergistic effect in $\mathrm{BE}(2)-\mathrm{C}$ cells and a moderate additive effect in SMS-KCNR cells. While the BE(2)-C isobologram suggests synergism by comparison with the line of Loewe additivity, this may be at least in part a consequence of independent reductions in cell proportion (Bliss independence). We showed that treatment with a combination of

A

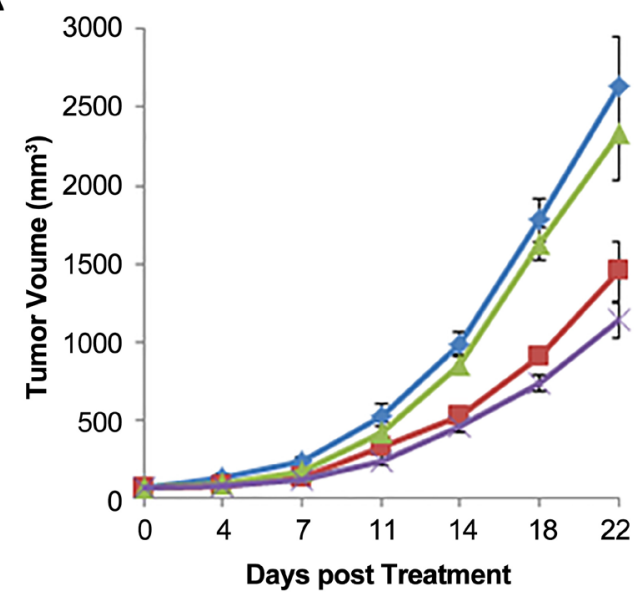

B

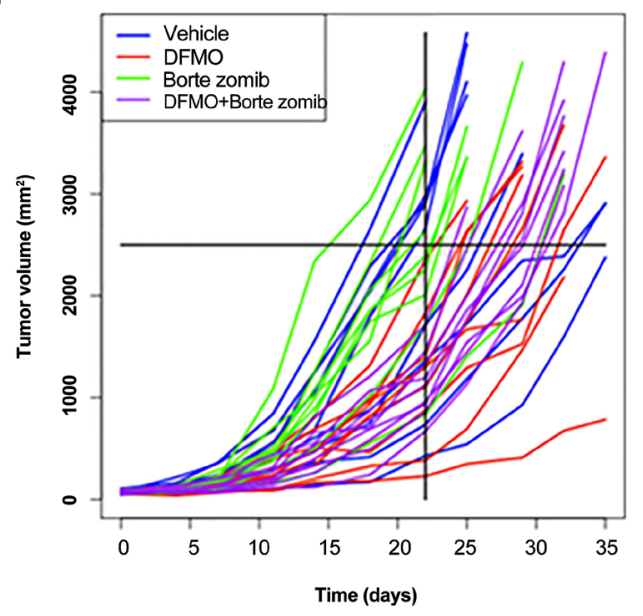

Figure 5. DFMO and bortezomib reduced tumor volumes in NB xenograft mice. Mice were injected with SMS-KCNR NB cells and treated with $2 \%$ DFMO and/or $0.5 \mathrm{mg} / \mathrm{kg}$ bortezomib twice a week. (A) Average tumor size was quantified using caliper measurements. Group 1, Vehicle; Group 2, 2\% DFMO in drinking water; Group 3, Bortezomib $0.5 \mathrm{mg} / \mathrm{kg}$ IP injection twice weekly; Group 4, 2\% DFMO in drinking water and Bortezomib $0.5 \mathrm{mg} / \mathrm{kg}$ IP injection twice weekly; (B) Growth curves of individual mouse in all four groups. 
DFMO and bortezomib inhibited LIN28, its downstream molecules, as well as glycolytic metabolism in both cell lines. Our mechanistic studies further demonstrated that bortezomib inhibited cell proliferation through activation of apoptotic pathways whereas DFMO mediated its effect through other pathways independent of apoptosis. In vivo studies using xenograft mice of SMS-KCNR cells revealed that DFMO as single agent or in combination with bortezomib significantly inhibited tumor growth suggesting a clinical relevance of this drug combination.

Bortezomib as a single agent treatment yielded a decrease in cellular viability compared to vehicle control while DFMO exhibits a linear response to increasing drug concentration until reaching a sudden drop in cellular proliferation at a high-dose of DFMO drug. These results suggest bortezomib may induce continuous inhibition of cell growth via cell death while DFMO is likely to be characterized as bimodal with both cytostatic and cytotoxic effects. This notion was further supported by our finding that bortezomib induced cleaved caspase- 3 protein levels, an apoptotic marker, while DFMO did not significantly. Of significant interest, treatment with DFMO and bortezomib inhibited expression of MYCN and LIN28B proteins in both NB cell lines. Amplification of $M Y C N$ is the most consistent and reliable indicator for aggressiveness and relapse in HRNB [36] [37]. LIN28B, through repression of the let-7 miRNAs, results in elevated MYCN protein expression in neuroblastoma cells [21] [38]. Recent studies have suggested that high LIN28B expression was an independent risk factor for adverse outcome in neuroblastoma [21] [39]. Therefore, reduction of LIN$28 \mathrm{~B}$ and MYCN expression in response to DFMO and bortezomib treatment provides therapeutic implications targeting these tumor drivers and support for the use of DFMO in combination with bortezomib in the treatment of high-risk neuroblastoma.

Interestingly, sensitivities of NB cells to DFMO and bortezomib were correlated with LIN28B transcript levels. Previously, we reported that BE(2)-C cells expressed high levels of LIN28B and MYCN whereas SMS-KCNR cells expressed high MYCN but low LIN28B transcripts [25]. We observed that combination therapy of DFMO and bortezomib produced higher synergistic effect in $\mathrm{BE}(2)-\mathrm{C}$ cells as compared to SMS-KCNR cells, which correlated with their LIN28 expression levels. These results also suggest that although DFMO and bortezomib act on different targets, they may mediate their actions, at least partly, through a common mechanism involving LIN28. DFMO works by irreversibly binding to and inhibiting ODC, the rate limiting enzyme in polyamine biosynthesis and the upstream regulator of LIN28 expression [25] [40]. Polyamines are also shown to regulate NF-kB pathway [41]. Bortezomib, on the other hand, is a proteasome inhibitor that prevents degradation of IkB, the inhibitor of NF-kB [28]. NF-kB is a transcription factor known to regulate expression of variety of genes in cell proliferation and differentiation pathways including antiapoptotic genes and proinflammatory cytokines [42]. Studies have linked a role of NF-kB in chemoresistance, metastasis and recurrence in high-risk neuroblastoma [43] [44]. NF- 
$\mathrm{kB}$ is known to activate LIN28 transcription directly [29]. These suggest that polyamine depletion through DFMO or proteasome inhibition through bortezomib should inhibit LIN28 pathway. Indeed, we found inhibition of NF-kB expression by DFMO and bertezomib in NB cells associated with LIN28 downregulation. Although, both drugs inhibit NF-kB, only bortezomib caused activation of apoptotic pathway in these cells. A similar effect was seen in combination treatment suggest that DFMO did not interfere in bortezomib induced apoptosis.

ATP-per-cell assays provided an experimental application for analyzing changes in bioenergetics of NB cell lines treated with DFMO and bortezomib. Studies have shown that LIN28/Let-7 pathway plays as an upstream regulator of glycolytic metabolic activity in cells [45]. Interestingly, recent studies have shown that CSCs thrive in anaerobic conditions due to their dependence on glycolytic metabolism for ATP production [46]. Glycolytic metabolism is often high in cancers due to a phenomenon called the "Warburg effect" when cancer cells are reprogramed to produce ATP primarily via glycolytic metabolism as opposed to oxidative phosphorylation metabolism [47] [48] [49]. Our data showed significant decreased ATP-per-cell activity in both BE(2)-C and SMSKCNR cells after combination treatment as compared to vehicle or single agent treatment which indicates that the drug combination may be an effective treatment to target glycolytic metabolism in cancers and specifically CSCs. To further examine this possibility, we investigated the effect of DFMO, bortezomib, or the combination treatment in tumor-bearing NB xenograft mice.

Significant decreased in tumor volumes of SMS-KCNR xenograft mice treated with a combination of DFMO and bortezomib as compared to control mice supported the in vitro findings that DFMO and bortezomib inhibits NB tumor cell growth, induced apoptosis and decreased glycolytic metabolism. While DFMO alone produced similar reduction in tumor size in SMS-KCNR xenograft mice although it only had moderate inhibition of LIN28 pathway molecules and ATP production in vitro, which suggests that DFMO may be more effective in vivo. This is in consistent with a recent clinical trial report, which demonstrated that HRNB patients treated with low dose DFMO as single agent therapy had positive response rate [24]. Our results further emphasized that DFMO may target specific population of cells within the tumor environment, namely CSC cells. Since, DFMO does not cause cell death, most likely it induced differentiation of CSC cells. In contrary, bortezomib, at the dose examined, had little effect on tumor growth in these mice. Propitiously, bortezomib did not produce any antagonistic effect on DFMO mediated reduction of tumor growth with slight further reduction in size with the combination.

\section{Conclusion}

This study is the first to support DFMO in combination with bortezomib as a possible treatment for NB targeting the MYCN, LIN28 and NFkB pathways. This is important since MYCN and LIN28 overexpression have been shown to be independent risk factors for adverse outcome in neuroblastoma. Future laboratory 
analysis and clinical studies will provide insight to the role of DFMO and bortezomib specifically in CSCs which utilize the LIN28/Let-7 pathway. Due to the high rates of relapse and metastatic disease for children with NB, combination treatments targeting several pathways, specifically in cancer initiating cells, are essential to provide greater opportunities for remission and long-term survival to patients.

\section{Acknowledgements}

This work was supported by the St. Baldrick's Foundation, Beat NB Foundation, and Charles and Meryl Witmer Foundation and donations from many families and supporters of neuroblastoma research. We thank Dr. Sangeeta Yendrembam for reviewing and editing the manuscript.

\section{References}

[1] Mahoney, N.R., Liu, G.T., Menacker, S.J., Wilson, M.C., Hogarty, M.D. and Maris, J.M. (2006) Pediatric Horner Syndrome: Etiologies and Roles of Imaging and Urine Studies to Detect Neuroblastoma and Other Responsible Mass Lesions. American Journal of Ophthalmology, 142, 651-659. https://doi.org/10.1016/j.ajo.2006.05.047

[2] Park, J.R., Eggert, A. and Caron, H. (2010) Neuroblastoma: Biology, Prognosis, and Treatment. Hematology/Oncology Clinics of North America, 24, 65-86. https://doi.org/10.1016/j.hoc.2009.11.011

[3] Matthay, K.K. (2013) Targeted Isotretinoin in Neuroblastoma: Kinetics, Genetics, or Absorption. Clinical Cancer Research, 19, 311-313. https://doi.org/10.1158/1078-0432.CCR-12-3313

[4] Wagner, L.M. and Danks, M.K. (2009) New Therapeutic Targets for the Treatment of High-Risk Neuroblastoma. Journal of Cellular Biochemistry, 107, 46-57. https://doi.org/10.1002/jcb.22094

[5] Pinto, N.R., Applebaum, M.A., Volchenboum, S.L., Matthay, K.K., London, W.B., Ambros, P.F., Nakagawara, A., Berthold, F., Schleiermacher, G., Park, J.R., Valteau-Couanet, D., Pearson, A.D. and Cohn, S.L. (2015) Advances in Risk Classification and Treatment Strategies for Neuroblastoma. Journal of Clinical Oncology, 33, 3008-3017. https://doi.org/10.1200/JCO.2014.59.4648

[6] Ishii, H., Iwatsuki, M., Ieta, K., Ohta, D., Haraguchi, N., Mimori, K. and Mori, M. (2008) Cancer Stem Cells and Chemoradiation Resistance. Cancer Science, 99, 1871-1877. https://doi.org/10.1111/j.1349-7006.2008.00914.x

[7] Zhou, B.B., Zhang, H., Damelin, M., Geles, K.G., Grindley, J.C. and Dirks, P.B. (2009) Tumour-Initiating Cells: Challenges and Opportunities for Anticancer Drug Discovery. Nature Reviews Drug Discovery, 8, 806-823. https://doi.org/10.1038/nrd2137

[8] Fornari, C., Beccuti, M., Lanzardo, S., Conti, L., Balbo, G., Cavallo, F., Calogero, R.A. and Cordero, F. (2014) A Mathematical-Biological Joint Effort to Investigate the Tumor-Initiating Ability of Cancer Stem Cells. PLoS One, 9, e106193. https://doi.org/10.1371/journal.pone.0106193

[9] Dontu, G., Al-Hajj, M., Abdallah, W.M., Clarke, M.F. and Wicha, M.S. (2003) Stem Cells in Normal Breast Development and Breast Cancer. Cell Proliferation, 36, 5972. https://doi.org/10.1046/j.1365-2184.36.s.1.6.x

[10] O'Brien, C.A., Pollett, A., Gallinger, S. and Dick, J.E. (2007) A Human Colon Can- 
cer Cell Capable of Initiating Tumour Growth in Immunodeficient Mice. Nature, 445, 106-110. https://doi.org/10.1038/nature05372

[11] Tirode, F., Laud-Duval, K., Prieur, A., Delorme, B., Charbord, P. and Delattre, O. (2007) Mesenchymal Stem Cell Features of Ewing Tumors. Cancer Cell, 11, 421429.

[12] Ross, R.A. and Spengler, B.A. (2007) Human Neuroblastoma Stem Cells. Seminars in Cancer Biology, 17, 241-247.

[13] Malik, F., Korkaya, H., Clouthier, S.G. and Wicha, M.S. (2012) Lin28 and HER2: Two Stem Cell Regulators Conspire to Drive Aggressive Breast Cancer. Cell Cycle, 11, 2780-2781. https://doi.org/10.4161/cc.21395

[14] Viswanathan, S.R., Powers, J.T., Einhorn, W., Hoshida, Y., Ng, T.L., Toffanin, S., O'Sullivan, M., Lu, J., Phillips, L.A., Lockhart, V.L., Shah, S.P., Tanwar, P.S., Mermel, C.H., Beroukhim, R., Azam, M., Teixeira, J., Meyerson, M., Hughes, T.P., Llovet, J.M., Radich, J., Mullighan, C.G., Golub, T.R., Sorensen, P.H. and Daley, G.Q. (2009) Lin28 Promotes Transformation and Is Associated with Advanced Human Malignancies. Nature Genetics, 41, 843-848. https://doi.org/10.1038/ng.392

[15] Moss, E.G., Lee, R.C. and Ambros, V. (1997) The Cold Shock Domain Protein LIN-28 Controls Developmental Timing in C. Elegans and Is Regulated by the Lin-4 RNA. Cell, 88, 637-646.

[16] Wang, T., Wang, G., Hao, D., Liu, X., Wang, D., Ning, N. and Li, X. (2015) Aberrant Regulation of the LIN28A/LIN28B and Let-7 Loop in Human Malignant Tumors and Its Effects on the Hallmarks of Cancer. Molecular Cancer, 14, 125. https://doi.org/10.1186/s12943-015-0402-5

[17] King, C.E., Cuatrecasas, M., Castells, A., Sepulveda, A.R., Lee, J.S. and Rustgi, A.K. (2011) LIN28B Promotes Colon Cancer Progression and Metastasis. Cancer Research, 71, 4260-4268. https://doi.org/10.1158/0008-5472.can-10-4637

[18] Kong, D., Banerjee, S., Ahmad, A., Li, Y., Wang, Z., Sethi, S. and Sarkar, F.H. (2010) Epithelial to Mesenchymal Transition Is Mechanistically Linked with Stem Cell Signatures in Prostate Cancer Cells. PLoS ONE, 5, e12445. https://doi.org/10.1371/journal.pone.0012445

[19] Yu, F., Yao, H., Zhu, P., Zhang, X., Pan, Q., Gong, C., Huang, Y., Hu, X., Su, F., Lieberman, J. and Song, E. (2007) Let-7 Regulates Self Renewal and Tumorigenicity of Breast Cancer Cells. Cell, 131, 1109-1123.

[20] Meirelles, K., Benedict, L.A., Dombkowski, D., Pepin, D., Preffer, F.I., Teixeira, J., Tanwar, P.S., Young, R.H., MacLaughlin, D.T., Donahoe, P.K. and Wei, X. (2012) Human Ovarian Cancer Stem/Progenitor Cells Are Stimulated by Doxorubicin But Inhibited by Mullerian Inhibiting Substance. Proceedings of the National Academy of Sciences of the United States, 109, 2358-2363.

https://doi.org/10.1073/pnas.1120733109

[21] Molenaar, J.J., Domingo-Fernandez, R., Ebus, M.E., Lindner, S., Koster, J., Drabek, K., Mestdagh, P., van Sluis, P., Valentijn, L.J., van Nes, J., Broekmans, M., Haneveld, F., Volckmann, R., Bray, I., Heukamp, L., Sprussel, A., Thor, T., Kieckbusch, K., Klein-Hitpass, L., Fischer, M., Vandesompele, J., Schramm, A., van Noesel, M.M., Varesio, L., Speleman, F., Eggert, A., Stallings, R.L., Caron, H.N., Versteeg, R. and Schulte, J.H. (2012) LIN28B Induces Neuroblastoma and Enhances MYCN Levels via Let-7 Suppression. Nature Genetics, 44, 1199-1206. https://doi.org/10.1038/ng.2436

[22] Samal, K., Zhao, P., Kendzicky, A., Yco, L.P., McClung, H., Gerner, E., Burns, M., Bachmann, A.S. and Sholler, G. (2013) AMXT-1501, a Novel Polyamine Transport Inhibitor, Synergizes with DFMO in Inhibiting Neuroblastoma Cell Proliferation by 
Targeting Both Ornithine Decarboxylase and Polyamine Transport. International Journal of Cancer, 133, 1323-1333. https://doi.org/10.1002/ijc.28139

[23] Lange, I., Geerts, D., Feith, D.J., Mocz, G., Koster, J. and Bachmann, A.S. (2014) Novel Interaction of Ornithine Decarboxylase with Sepiapterin Reductase Regulates Neuroblastoma Cell Proliferation. Journal of Molecular Biology, 426, 332-346.

[24] Saulnier Sholler, G.L., Gerner, E.W., Bergendahl, G., MacArthur, R.B., VanderWerff, A., Ashikaga, T., Bond, J.P., Ferguson, W., Roberts, W., Wada, R.K., Eslin, D., Kraveka, J.M., Kaplan, J., Mitchell, D., Parikh, N.S., Neville, K., Sender, L., Higgins, T., Kawakita, M., Hiramatsu, K., Moriya, S.S. and Bachmann, A.S. (2015) A Phase I Trial of DFMO Targeting Polyamine Addiction in Patients with Relapsed/Refractory Neuroblastoma. PLoS ONE, 10, e0127246.

https://doi.org/10.1371/journal.pone.0127246

[25] Lozier, A.M., Rich, M.E., Grawe, A.P., Peck, A.S., Zhao, P., Chang, A.T., Bond, J.P. and Sholler, G.S. (2015) Targeting Ornithine Decarboxylase Reverses the LIN28/Let-7 Axis and Inhibits Glycolytic Metabolism in Neuroblastoma. Oncotarget, 6, 196-206.

[26] Cusack, J.C., Liu, R., Houston, M., Abendroth, K., Elliott, P.J., Adams, J. and Baldwin, A.S. (2001) Enhanced Chemosensitivity to CPT-11 with Proteasome Inhibitor PS-341: Implications for Systemic Nuclear Factor-kappaB Inhibition. Cancer Research, 61, 3535-3540.

[27] Kane, R.C., Bross, P.F., Farrell, A.T. and Pazdur, R. (2003) Velcade: U.S. FDA Approval for the Treatment of Multiple Myeloma Progressing on Prior Therapy. Oncologist, 8, 508-513. https://doi.org/10.1634/theoncologist.8-6-508

[28] Chen, D., Frezza, M., Schmitt, S., Kanwar, J. and Dou, Q.P. (2011) Bortezomib as the First Proteasome Inhibitor Anticancer Drug: Current Status and Future Perspectives. Current Cancer Drug Targets, 11, 239-253. https://doi.org/10.2174/156800911794519752

[29] Iliopoulos, D., Hirsch, H.A. and Struhl, K. (2009) An Epigenetic Switch Involving NF-kappaB, Lin28, Let-7 MicroRNA, and IL6 Links Inflammation to Cell Transformation. Cell, 139, 693-706.

[30] Michaelis, M., Fichtner, I., Behrens, D., Haider, W., Rothweiler, F., Mack, A., Cinatl, J., Doerr, H.W. and Cinatl, J. (2006) Anti-Cancer Effects of Bortezomib against Chemoresistant Neuroblastoma Cell Lines in Vitro and in Vivo. International Journal of Oncology, 28, 439-446. https://doi.org/10.3892/ijo.28.2.439

[31] Combaret, V., Boyault, S., Iacono, I., Brejon, S., Rousseau, R. and Puisieux, A. (2008) Effect of Bortezomib on Human Neuroblastoma: Analysis of Molecular Mechanisms Involved in Cytotoxicity. Molecular Cancer, 7, 50.

https://doi.org/10.1186/1476-4598-7-50

[32] Brignole, C., Marimpietri, D., Pastorino, F., Nico, B., Di Paolo, D., Cioni, M., Piccardi, F., Cilli, M., Pezzolo, A., Corrias, M.V., Pistoia, V., Ribatti, D., Pagnan, G. and Ponzoni, M. (2006) Effect of Bortezomib on Human Neuroblastoma Cell Growth, Apoptosis, and Angiogenesis. Journal of the National Cancer Institute, 98, 1142 1157. https://doi.org/10.1093/jnci/djj309

[33] Berenson, J.R., Matous, J., Swift, R.A., Mapes, R., Morrison, B. and Yeh, H.S. (2007) A Phase I/II Study of Arsenic Trioxide/Bortezomib/Ascorbic Acid Combination Therapy for the Treatment of Relapsed or Refractory Multiple Myeloma. Clinical Cancer Research, 13, 1762-1768. https://doi.org/10.1158/1078-0432.ccr-06-1812

[34] Valentiner, U., Haane, C., Nehmann, N. and Schumacher, U. (2009) Effects of Bortezomib on Human Neuroblastoma Cells in Vitro and in a Metastatic Xenograft Model. Anticancer Research, 29, 1219-1225. 
[35] Armstrong, M.B., Schumacher, K.R., Mody, R., Yanik, G.A., Opipari, A.W. and Castle, V.P. (2008) Bortezomib as a Therapeutic Candidate for Neuroblastoma. Journal of Experimental Therapeutics \& Oncology, 7, 135-145.

[36] Brodeur, G.M. (2003) Neuroblastoma: Biological Insights into a Clinical Enigma. Nature Reviews Cancer, 3, 203-216. https://doi.org/10.1038/nrc1014

[37] Huang, M. and Weiss, W.A. (2013) Neuroblastoma and MYCN. Cold Spring Harbor Perspectives in Medicine, 3, a014415. https://doi.org/10.1101/cshperspect.a014415

[38] Powers, J.T., Tsanov, K.M., Pearson, D.S., Roels, F., Spina, C.S., Ebright, R., Seligson, M., de Soysa, Y., Cahan, P., Theissen, J., Tu, H.C., Han, A., Kurek, K.C., LaPier, G.S., Osborne, J.K., Ross, S.J., Cesana, M., Collins, J.J., Berthold, F. and Daley, G.Q. (2016) Multiple Mechanisms Disrupt the Let-7 microRNA Family in Neuroblastoma. Nature, 535, 246-251. https://doi.org/10.1038/nature18632

[39] Diskin, S.J., Capasso, M., Schnepp, R.W., Cole, K.A., Attiyeh, E.F., Hou, C., Diamond, M., Carpenter, E.L., Winter, C., Lee, H., Jagannathan, J., Latorre, V., Iolascon, A., Hakonarson, H., Devoto, M. and Maris, J.M. (2012) Common Variation at 6q16 within HACE1 and LIN28B Influences Susceptibility to Neuroblastoma. Nature Genetics, 44, 1126-1130. https://doi.org/10.1038/ng.2387

[40] Paz, E.A., LaFleur, B. and Gerner, E.W. (2014) Polyamines Are Oncometabolites That Regulate the LIN28/Let-7 Pathway in Colorectal Cancer Cells. Molecular Carcinogenesis, 53, E96-E106. https://doi.org/10.1002/mc.22051

[41] Facchini, A., Borzi, R.M., Marcu, K.B., Stefanelli, C., Olivotto, E., Goldring, M.B., Facchini, A. and Flamigni, F. (2005) Polyamine Depletion Inhibits NF-kappaB Binding to DNA and Interleukin-8 Production in Human Chondrocytes Stimulated by Tumor Necrosis Factor-Alpha. Journal of Cellular Physiology, 204, 956-963. https://doi.org/10.1002/jcp.20368

[42] Naugler, W.E. and Karin, M. (2008) NF-kappaB and Cancer-Identifying Targets and Mechanisms. Current Opinion in Genetics \& Development, 18, 19-26.

[43] Brown, R.E., Tan, D., Taylor, J.S., Miller, M., Prichard, J.W. and Kott, M.M. (2007) Morphoproteomic Confirmation of Constitutively Activated mTOR, ERK, and NF-kappaB Pathways in High Risk Neuro-Blastoma, with Cell Cycle and Protein Analyte Correlates. Annals of Clinical \& Laboratory Science, 37, 141-147.

[44] Zhi, Y., Lu, H., Duan, Y., Sun, W., Guan, G., Dong, Q. and Yang, C. (2015) Involvement of the Nuclear Factor-kappaB Signaling Pathway in the Regulation of CXC Chemokine Receptor-4 Expression in Neuroblastoma Cells Induced by Tumor Necrosis Factor-Alpha. International Journal of Molecular Medicine, 35, 349-357.

[45] Zhu, H., Shyh-Chang, N., Segre, A.V., Shinoda, G., Shah, S.P., Einhorn, W.S., Takeuchi, A., Engreitz, J.M., Hagan, J.P., Kharas, M.G., Urbach, A., Thornton, J.E., Triboulet, R., Gregory, R.I., Consortium, D., Investigators, M., Altshuler, D. and Daley, G.Q. (2011) The Lin28/Let-7 Axis Regulates Glucose Metabolism. Cell, 147, 81-94.

[46] D’Angelo, R.C. and Wicha, M.S. (2010) Stem Cells in Normal Development and Cancer. Progress in Molecular Biology and Translational Science, 95, 113-158.

[47] Warburg, O. (1956) On the Origin of Cancer Cells. Science, 123, 309-314. https://doi.org/10.1126/science.123.3191.309

[48] Kushner, B.H., Yeung, H.W., Larson, S.M., Kramer, K. and Cheung, N.K. (2001) Extending Positron Emission Tomography Scan Utility to High-Risk Neuroblastoma: Fluorine-18 Fluorodeoxyglucose Positron Emission Tomography as Sole Imaging Modality in Follow-Up of Patients. Journal of Clinical Oncology, 19, 3397-405. https://doi.org/10.1200/jco.2001.19.14.3397 
[49] Denko, N.C. (2008) Hypoxia, HIF1 and Glucose Metabolism in the Solid Tumour. Nature Reviews Cancer, 8, 705-713. https://doi.org/10.1038/nrc2468

Submit or recommend next manuscript to SCIRP and we will provide best service for you:

Accepting pre-submission inquiries through Email, Facebook, LinkedIn, Twitter, etc. A wide selection of journals (inclusive of 9 subjects, more than 200 journals)

Providing 24-hour high-quality service

User-friendly online submission system

Fair and swift peer-review system

Efficient typesetting and proofreading procedure

Display of the result of downloads and visits, as well as the number of cited articles Maximum dissemination of your research work

Submit your manuscript at: http://papersubmission.scirp.org/

Or contact jct@scirp.org 